\title{
CLINICAL OBSERVATIONS ON INTERFERENCES OF EARLY FATHER ABSENCE IN THE ACHIEVEMENT OF FEMININITY
}

\author{
Rebecca Lohr, A.C.S.W. \\ Cecily Legg, M.S.W. \\ Allen E. Mendell, M.D. \\ Barbara S. Riemer, Ph.D.
}

\begin{abstract}
In clinical work, we have observed that the loss of the father through divorce has a significant effect on the young girl's developing sense of feminity. This paper briefly reviews the research findings from sex-role development theory and psychoanalytic theory, and presents clinical discussions of latency aged girls whose parents divorced during their daughter's early and oedipal years. The most common defensive or coping patterns seen in these child patients during latency are identified, with clinical material presented to illustrate both the existence of these patterns and implications for treatment.
\end{abstract}

In our clinical work with children of divorce, we have observed that female children often react with a profound sense of loss to the departure of the father from the family unit. The plaintive cry, "Why did Daddy leave us?" is not uncommon. We see not only the acute sense of loss experienced by these children, but also the effect of the father's absence on the course of development over time. 'The important role played by the father in the development of the girl's sense of femininity is recognized in both psychoanalytic theory and findings from studies of sex role development. While the effects of father absence on identifica-

'Kalter and Rembar (1981) report that nearly two-thirds of their sample of Children's Psychiatric Hospital patients had experienced parental divorce over five years earlier. 
tion in male children have been reported extensively in the literature, the effects of father absence due to divorce on feminine development have only more recently been investigated, and with mixed findings. After a short review of research findings based on sex-role development theory and psychoanalytic theory, we will focus our discussion on clinical observation of latency aged girls whose parents divorced in their children's early and oedipal years.

\section{Research Literature}

In his comprehensive literature review of the effects of father absence on personality development, Biller (1981) cites consistent findings that males are adversely affected by father absence, while the findings for females are often conflicting and contradictory. The one area that seems most strikingly affected is that of the girl's feminine development and heterosexual interactions, particularly observed during adolescence. Recent research has supported the conclusion that girls are at least as much influenced in their social and heterosexual development by father absence as are boys (e.g., Biller, 1971; Biller and Weiss, 1970; Hetherington, 1972; Wallerstein and Kelly, 1976, 1980). Anthropological evidence suggests that low father availability is associated with sexual conflicts for girls as well as for boys (Brown, 1963; Stephens, 1962). In a number of studies, women who had experienced father absence early in life reported poor heterosexual adjustment (e.g., Leonard, 1966; Neubauer, 1960) and unsatisfactory sexual relationships (Jacobson and Ryder, 1969). Biller (1971) concludes that father absence seems to have more effect on the girl's ability to function in interpersonal and heterosexual relationships than on her sex role preference.

The investigations of two psychologists, Hetherington (1979) and Kalter (1985), have contributed significantly to understanding the impact of father absence on feminine development. Hetherington suggests that there are different patterns of effects of father absence on the development of girls and boys. For boys, father absence results in disruptions in sex role typing during the preschool years. With increasing age and extrafamilial interaction, these effects are attenuated or transformed into compensatory masculinity. For girls, the effects of father absence are delayed and appear during adolescence manifested as an inability to interact appropriately with males, rather than deviations from appropriate sex typing or in interactions with females. Greater dependency on female adults, however, was observed. Hetherington (1972) compared girls from three different family backgrounds. In one group the girls lived at home with both parents, in another the girls' fathers were deceased and the girls lived with their mothers, and in the third 
the girls' parents were divorced and the girls subsequently had minimal contact with their fathers. She found that daughters of divorce sought attention from men more often, reported being the most active sexually, and had the lowest self-esteem. The effects of early father separation were more pronounced than later separation. While she noted different coping patterns in girls who had lost their fathers through death than in those whose loss was through divorce, she proposed that for both groups the lack of opportunity for constructive interaction with a loving, attentive father resulted in apprehension and inadequate skills in relating to men. In later work she reported that the impact of marital discord and divorce is more pervasive and enduring for boys than for girls, and that disturbances in social and emotional development in girls have "largely disappeared two years after the divorce, although they may reemerge at adolescence in the form of disruptions in heterosexual relations" (Hetherington, 1979, p. 853).

In Kalter's 1977 comparison of children referred to an outpatient clinic for evaluation, he reported that adolescent daughters of divorce were more likely to present with 1) precocious sexual activity, 2) substance abuse, 3) running away from home than their counterparts from intact households. He also reports (1984) that adolescent girls who seemed most troubled had experienced parental divorce in early childhood prior to the elementary school years and had little or no contact with their fathers for an extended period of time. "Despite an apparent, and perhaps actual, good adjustment until adolescence, this new development appeared to precipitate corrosively hostile interactions with the custodial mother, precocious sexual activity, and involvement with drugs and/or alcohol" (p. 539). He postulates that "underlying these behavioral problems seem to be intense separation conflicts vis-a-vis mother and an internalized sense of femininity as being unworthwhile" (p. 539). An emotionally peripheral and often physically distant father seemed related to a shift in family processes that increased the girl's vulnerability to developing an enmeshed relationship with the mother. In a report by Kalter et al. (1985), comparing elementary school aged children from intact and divorced homes, no evidence was found to support the proposition that parental divorce is associated with disrupted acquisition of academic knowledge in this sample of pre-adolescent girls. However, he found that third grade girls who on the average were toddlers when their parents' marriages ended had lower perceived social and physical competency scores than their peers from intact households. He concludes that, "Perhaps disruption in family life and the lack of a centrally involved father has a particularly negative effect on subsequent social and physical concept when the girl is a young preschooler" (p. 540). This result is consistent with those studies which have found 
an association between parental divorce and negative sequelae when girls are younger than six years old at the time of the separation (e.g., Hetherington, 1972 and Kalter and Rembar, 1981).

Wallerstein and Kelly (1975) in their study of the effects of parental divorce on the pre-school child found that a significantly higher percentage of the girls from three and three-fourths to six years were in significantly worse psychological condition at one year follow-up compared to the boys in the sample. These findings, as they note, are at variance with the normal sexual distribution of child-patient population where boys predominate. The girls in this oedipal age sample presented a clinical picture of "prolonged investment in oedipal fantasies, diminished self-esteem, and delayed entrance into latency" (p. 610). In Wallerstein's (1984) 10-year follow-up of this population, she describes "striking repression" of divorce-related feelings and experiences. However, for $30 \%$, the divorce remained "a central aspect of their lives and evoked strong feelings, tears and profound sadness as they spoke of their loneliness and continued sense of deprivation" (p. 451).

Other studies have reported the long-term effects of parental divorce on adult daughters' heterosexual and marital relationships, with higher incidence of marital problems and divorce (Kulka and Weingarten, 1979). Heterosexual adjustment difficulties, and feelings of diminished feminine self-worth in adolescent and adult daughters of divorce were reported in Wallerstein's 10-year follow-up of children of divorce currently $19-27$ years old (1985).

\section{Psychoanalytic Literature}

Edgecombe et al. (1976), after reviewing the psychoanalytic literature on the negative oedipal phase in girls, raise important questions for consideration. How much difficulty does the girl really have in achieving femininity? When she has difficulty, to what extent is this due to internal factors, and how important are environmental influences? They conclude that,

Given optimal conditions, it appears that the girl does not have great difficulty in achieving femininity. She may move quite smoothly into an oedipal phase in which positive aspects dominate over negative ones, i.e., in which feminine trends outweigh masculine ones, regardless of normal penis envy. . . In those girls who did have difficulty in achieving predominantly positive oedipal relationships, our material suggests that environmental factors played a crucial role in distorting their development, especially the presence or absence of the father, and the mother's failure to act as a suitable model for identification (p. 58). 
REBECCA LOHR ET AL.

They present two cases in which the girls evidenced conflict in the oedipal phase. In the first case, the father had left when the daugher was $31 / 4$ years old and the mother was severely depressed.

\begin{abstract}
Throughout most of the treatment oscillation between positive and negative aspects of the Oedipus complex was apparent, and the negative swings seemed to become increasingly defensive. One has the impression of a child struggling to achieve a feminine role and establish herself in the positive oedipal position, but who is forced wearily to retreat into the negative oedipal position, identifying with the phallic male particularly to cope with her own sense of loss of the positive oedipal object (and of the father in his wider role), partly to compensate mother for the loss of the father and so prevent her retreating into depression (p. 53).
\end{abstract}

In the second case, external circumstances were more favorable to steady development, and they note that the child's environment is of considerable importance in reinforcing positive or negative aspects of oedipal development. Another case was briefly described in which the frequent retreats from positive to negative oedipal relationships were understood as attempts primarily to adapt to the frustration of positive oedipal relationships and to the absence of the father.

In a discussion of the development of gender identity, Mächtlinger (1981) concludes that a relationship with the opposite sex is necessary for the child to experience true gender identity. This means that the sense of female gender must become extended to include wishes, fantasies, and impulses directed toward boys and men. A secure, loving, and reasonably continuous relationship with the father throughout the preoedipal phases provides the matrix for the female child to experience being feminine. Fast (1979) expresses similarly that as the little girl establishes her gender identity, she begins to relate to each parent in specifically gender terms - to her mother as the same sex person with whom she can identify as a woman, and to her father as specifically male in relation to herself as specifically female. "These new orientations provide contexts within which she practices and elaborates the differentiated notions of femininity and masculinity she is developing" ( $p$. 451).

\title{
CLINICAL OBSERVATIONS
}

Our observations are based on clinical interventions with female children whose parents divorced during their oedipal and pre-oedipal years. During latency, these children presented with a range of sympto- 
matology and disturbances in their development which precipitated referral to Children's Psychiatric Hospital, University of Michigan, for evaluation and treatment. In an earlier reported study by Kalter and Rembar (1981) at the same institution, a sample of 144 child and adolescent patients, whose parents had divorced, presented with three most commonly occurring problems:

Subjective psychological problem (defined as anxiety, sadness, pronounced moodiness, phobias, and depression) $-63 \%$;

Poor grades or grades substantially below ability and/or recent past performance- $56 \%$;

Aggression toward parents-43\%

Important features of the subgroup of 32 latency aged girls were in the same order with $69 \%$ indicating subjective psychological distress, $47 \%$ academic problems, and $41 \%$ aggression toward parents. In their study, the hypotheses that divorce occurring during the critical stage (oedipal) and recency of divorce are related to the extent of distress and emotional disturbance did not receive support. They found, however, that the timing of marital dissolution did relate to difficulties the children experienced. Separation and divorce during the child's earliest years were associated with a significantly higher incidence of non-aggressive disturbances in the parent-child relationship in both the boy and girl latency age groups. They conclude that "When marital dissolution occurs at a time that youngsters are coping with the normal developmental task of separating from parents, particularly mother, a special vulnerability to separation difficulties in latency may be established (p. 97). They suggest that the occurrence of divorce during the child's early or oedipal years máy have differential effects on children which can be detected reliably during latency and even as far in the future as adolescence. In fact, adolescent girls who were oedipal-aged when their parents divorced showed more aggression towards parents and peers than adolescent girls who were pre- or post-oedipal when their parents divorced.

Based on our clinical experience with a number of latency aged and adolescent girls whose parents divorced during their oedipal years, we postulate that particular coping pattens emerge in response to the absence of the father, which may complicate the consolidation of positive feminine identification in many female children, and is observable during the latency years. We will explore the most common defensive or coping patterns seen in these child patients during latency and present clinical material to illustrate both the existence of these phenomena and implications for treatment: 1) intensified separation anxiety; 2) de- 
REBECCA LOHR ET AL.

nial and avoidance of feelings associated with loss of father; 3) identification with the lost object; 4) object hunger for males.

\section{Intensified Separation Anxiety and Some Associated Coping Patterns}

Many of the female children we have seen exhibit intensified anxiety around separating from mother after a disruption in the object tie to the father. An inhibition of aggression toward mother may ensue out of fear that she too may leave. This is often presented via clinging behavior, nighttime fears, and/or retreat to mother's bed. This may represent a regression from and a defense against oedipal level aggression and competition toward mother. Pre-oedipal aggressive feelings toward the mother may be acted out, leading to an increase in sadistic, controlling, and passive-aggressive behavior.

Clinical example: Tina was $51 / 2$ when her mother contacted us for evaluation. Her parents had separated eight months earlier and in the intervening months Tina reacted with feelings of loss, wistfulness for her father, and a general aura of sadness. Prior to the parental separation, Tina had been a happygo-lucky youngster - cheerful, adaptable, and flexible, who had a close, "special" relationship with her mother. Her father had a history of alcoholism and a relationship with Tina and her mother that ranged from warmth to physical abusiveness. Tina, with intelligence in the superior range, spoke of her understanding that her dad was sick and that was why he had left her and her mother. His contact with them was inconsistent and sporadic. Tina began to develop fears that her mother, too, might leave her. There was frequent bed-sharing, nocturnal enuresis, night terrors and clingy behavior. When Tina observed her mother crying, she would get her a box of Kleenex to "make her feel better."

Tina's clinical material revealed intense sadness over the loss of her father and enmeshment in the relationship with her mother. Drawings depicted the closeness of mother and daughter, with verbalized wishes to give the drawings to her mother. She would have liked to give pictures to her father, too, but he rarely came to visit and she did not know where he lived. Although she functioned well academically in kindergarten, she retreated from social interaction with peers into an isolated, withdrawn stance.

Tina was taking on a pseudo-adult, caretaking position vis-a-vis her mother. She used extensive denial, reaction formation, and turning of anger inward, presenting as a too good child who had to keep many feelings under wraps, intermingled with her acting out, controlling behavior. She had retreated from the positive oedipal position out of a wish to replace the father in order to retain her mother's love. She was developing an identification with her mother's defensive style including the self-perception of a passive, bereft victim of male aggression and rejection. Psychological testing revealed a youngster emotionally withdrawn from relationships and struggling to achieve independence from her mother. Suppression and intellectualization were employed to contain her feelings to the point that vitality and vibrancy were drained.

Tina was seen in psychotherapy by a female therapist for two years. Early themes were related to separation issues that surfaced in the transference when the therapist took a vacation. She became controlling, demanding that the therapist not leave or that she should at least arrange for an identical replacement. 
Play subsequently centered around Tina's wish to get rid of mother so that she could play with horses by herself, which she would corral and lock in barns to prevent them from leaving her, thereby attempting to gain control over her feelings of helpless desperation. Preoedipal experiences and conflicts were expressed in play in which she assumed the abusive, vindictive parent role and placed the therapist in the helpless, victimized position. She was extremely conflicted in terms of her ongoing longings for love and affection from her father. Out of her own feelings of disappointment, and to appease her mother, she assumed the stance of not wanting to maintain contact with her father. This did not mean, however, that she relinquished oedipal level fantasies, as they continued to surface in fantasy and play and when her mother had a date.

The last months of treatment were marked by Tina's need to block out any positive feelings about treatment and to assume a rejecting, hostile stance toward the therapist. In a very real sense, she had to become the active leavetaker, often leaving sessions early to ward off any painful longing, or sad feelings. Thus, the termination phase allowed her the opportunity to rework some of her feelings around the father's departure from the family.

In a follow-up telephone contact with the mother when Tina was $111 / 2$, Tina was described as having developed more positive feelings about herself as a girl who was becoming pubertal. She had developed a keen interest in Arabian horses which she owned and showed (a sublimation of her wishes toward the unavailable father) and was the first flutist in her school orchestra. Her adolescent adjustment particularly in terms of heterosexual relationships and continuing development of her sense of femininity remains to be seen.

\section{Identification with the Lost Object}

Another commonly observed phenomenon in latency aged girls is the identification with the infrequently seen father in order to retain closeness with him. Sometimes this serves as a means of coping with the sense of loss of the positive oedipal object, and also perhaps to compensate the mother for her loss of the father. When the girl attempts to take father's place in the single mother, post-divorce household, this can lead to a prolonged and intensified negative oedipal phase. The movement toward identification with the mother is hindered by the little girl's perception of her mother as no longer the object of her father's love, but of rejection.

Clinical example: Lisa, age 9, presented with moodiness and unhappiness. In addition, her mother was concerned about her "too boyish" behavior and her selection of largely male friends. Mother reported that girls did not want to play with Lisa because she did not wear a dress and play with dolls, and preferred playing baseball in her jeans with the boys. Her parents divorced when Lisa was six, after her mother "stumbled suddenly onto her husband's extramarital affair." In the intervening years, Lisa strongly idealized and defended her father, rationalizing the long intervals between his visits. She reportedly spoke frequently of her father at school. Mother explicitly identified Lisa with the father's side of the family in a negative light, alleging that she was stubborn, obstinate, and "a cocky, nasty little snot" when she returned from visits with the paternal grandparents. 
In clinical evaluation,* Lisa nevertheless appeared quite feminine, but not frilly or ornate. Mother later reported that, in anticipation of the session with the male evaluator, Lisa had curled her hair the previous evening. Her material revealed her preoccupation with activities associated with her father and male playmates - her paternal aunt's swimming pool, a baseball game, and boxing with her younger brother. Subsequent evaluation sessions continued the theme as, for example, maintenance men building a playground for children and an anticipated camping trip with her father. She described her toughness in fights with school chums, and male peers of whom she was quite fond who moved away.

Lisa was seen as highly defended against any expression of anger or disappointment in her father. She dressed herself in a mantle of masculine toughness that veiled her need for succor and nurturance from others. She identified with the lost object, the male figure, to ward off feelings of loss and narcissistic injury associated with experiences of being left. Identification with her mother was complicated by her perception of mother on the one hand as the rejector of the desired father and on the other hand as the cast off, rejected female herself.

Outpatient treatment was recommended to help her deal with feelings of disappointment in her father's unavailability to her and the attendant negative self-feelings, and to foster the development of a positive sense of femininity. The male evaluator continued to see her in psychotherapy, allowing for the unfolding of the budding positive transference, and facilitating movement into the positive oedipal phase.

Denial and avoidance of feelings associated with loss of father are commonly seen as means of coping with painful feelings of narcissistic injury and as a defense against anger toward the disappointing oedipal object. The little girl may become fearful of entering into positive oedipal relationships with men, when she had experienced loss or she may become over seductive and over familiar. For many girls the relationship with their fathers becomes one in which they feel teased by the offers to visit, birthday gifts, trips, etc. only to experience repeated disappointments.

Clinical example: Diane, age 9, was five years old when her parents divorced. She subsequently lived with her mother and six-year-old sister, with contact with her father several times a year. Her mother described her as angry, unhappy, and "like she is premenstrual all the time." Mother questioned if Diane's "poor me" attitude and feelings of deprivation stemmed from her very minimal and unpredictable contact with her father. Mother was troubled by Diane's repeated experience of rejection when she attempted to re-establish contact with her father by telephone; however, if mother did not allow her to call, Diane would become very angry with her. In order to preserve her father's image as someone potentially accessible to her, she had to displace the anger and sense of deprivation onto her mother. Diane's mother was a soft, feminine-looking, blond-haired, blue-eyed woman out of a Botticelli painting; in sharp contrast, Diane was tomboyish, with short, cropped hair, wearing blue jeans and a Superman T-shirt. Diane spoke in an idealized way of her infrequent visits with her father-their guitar sings, shopping sprees, dinners out-as though they

\footnotetext{
*Matthew Leeds, Ph.D. was evaluator and therapist in this case.
} 
were frequent and rich experiences. Fond, even romantic feelings were expressed toward mother's past and current boyfriends. Longings for a more consistent relationship with a father figure emerged very poignantly as she spoke of her grandfather's taking her out for dinner once a week and that everyone in the family knew they "had a special relationship."

Diane had very solid peer relationships, in contrast to her argumentative, rivalrous relationship with her younger sister. She and her girlfriends liked to play with Barbie dolls after school, pretending to be teenagers, going out on dates, getting married, even having babies. Her conflicts in gender identity emerged in her life ambitions to be either a fireman or a female singer. With embarrassment, she revealed a dream in which her mother had grown a long nose.

Diane revealed solid latency aged functioning in many areas, but an active, ongoing struggle with oedipal issues reflected the trauma of her parents' divorce during that critical stage of development. She idealized the distant, relatively unavailable father, and denied her keen sense of disappointment in him. While her mother was portrayed consciously in a positive, nurturing way, the unconscious portrayal was of a ubiquitous phallic woman, whose aggressive and phallic properties were masked behind a benign exterior. Oedipal feelings were kept alive and fed by her mother's relationships with men of whom Diane would become fond, only to re-experience disappointment when the relationships ended. There was overdetermined anger toward her mother for not giving her a penis and for teasing her with and depriving her of oedipal objects. While her primary identification seemed to be with her feminine mother, there were also negative oedipal wishes to be the male figure with her mother.

Short-term treatment with a female therapist focused on exploring Diane's divorce-related feelings in displacement aimed at modifying the rigidity of her defensive style and fostering a wider range of expression of affect. Two years later in a telephone contact with her mother, it was learned that mother had remarried and that Diane was looking forward to being legally adopted by her stepfather with whom she had developed a warm, comfortable relationship. Prognosis for. Diane appears quite good given her solid ego functioning, the ongoing availability of her mother and the presence of a positive father figure during her adolescence.

\section{Oedipal Object Hunger}

Many girls who have infrequent, inconsistent contact during latency with their divorced fathers appear starved for contact with the male object of their feminine longings. Some express their wishes to be loved and cared for by a father figure or male therapist overtly, while others represent their desires in oral themes, when, for example, the father is depicted as the pizza delivery man, the deliverer of desirable food.

Clinical example: Joy was the only child of older parents who had continued to feud since their separation when Joy was $21 / 2$. When Joy was $61 / 2$ her mother sought help at the urging of her first grade teacher. In the classroom, 
Joy was distractible and excitable. She was ostracized by other children for "being silly," when she waved her arms or jumped up and down in excitement. At home, she seemed depressed and occasionally angry and aggressive. Her mother was a bright, educated woman in her mid-forties whose intellect and wit could be unleashed against her ex-husband or the male therapist in a devastating fashion. She had married her husband with a wish to have a child before her time clock ran out, and the parental relationship was stormy from the outset. As mother worked from the time Joy was 11 months old, she was cared for by multiple caretakers and teachers.

Joy was presented descriptively as a much more disturbed youngster than she appeared clinically. Thoughts of organically based problems were considered and rejected based on clinical observations. The neurological screening exam was negative. She presented as an adorable, yet seductive, little girl who was obviously intelligent, imaginative, and able to engage in and sustain objectrelated fantasy play without evidence of attention deficits or poor frustration tolerance. The most noticeable pathological characteristic was extreme object hunger, especially oedipal object hunger.

Within a few weeks of the start of therapy, Joy's behavioral problems abated. By the end of the semester, she was one of the most academically outstanding pupils in her class and, in addition, was one of the most popular, with two very special close friends. The course of therapy will be briefly discussed.*

Parent work was critical in this case, as it quickly became apparent based on Joy's interactions with the male therapist and mother's material that Joy was being overstimulated by exposure to and involvement in mother's ongoing relationship with Joy's father and another man, both of whom she called 'Daddy.' Joy's over-excitable behavior in school could be traced to the high level of stimulation she experienced when seeing her mother's boyfriend bathing nude and walking around the house. Her mother was unable to use good judgment in establishing reasonable boundaries and limits and typically saw Joy either as an extension of, or as a source of mothering for herself. Parent work aimed at giving the mother support to separate herself out from her daughter rather rapidly provided relief for Joy. Mother was able to develop the ability to cope with her sadness when her daughter was asked to spend the night at a friend's house. The therapist became an auxiliary ego to support healthier ego functioning in the mother. Simultaneously, Joy entered into a strong, positive transference relationship with her male therapist. Her hunger for attention from a male, her view of men as possessing some special "goodies" that had to be stolen or procured by seduction and then shared with mommy, her anger at mother for depriving her of the oedipal object, anxiety about separation from mother, battles with mother for autonomy, a protective and nurturing attitude toward her mother, and an intense need to please were early persistent themes in her treatment. The therapist had to set consistent limits on her excitable affect and overtly seductive behavior, which also served to reduce Joy's anxiety both within the sessions, the school arena and at home. Her overvaluation of men became expressed in drawings of large snowmen and playing out of treasure hunts, in which the sought out object emerged as the penis. Her feelings of deprivation of both the male object and the male organ and anger at her mother for being the instrument of her deprivation were available for interpretation that resulted in diminishing of angry affect and symptoms.

\footnotetext{
*Allen E. Mendell, M.D., was the therapist in this case.
} 
Dealing with father loss within the transference: Four months into treatment when her therapist was called out of the room, Joy became frightened that the therapist would leave her unexpectedly as her father had done. Her perception of her mother as having sent her father away, jailed for his bad behavior emerged. When the therapist went on a planned vacation, she spoke openly and poignantly of her sad feelings. Upon his return, Joy was reluctant to re-enter therapy, and the therapist interpreted her anger toward him for leaving her. Following adamant denial, she launched into a tirade against her father, "That little nerd who was so unreliable and never came on time for visits, sometimes disappearing for months without telling anyone." He did not pay child support, never listened to her when she talked, and took her to cheap restaurants. In later months, she spoke of her keep disappointment in her father when he did not come through for her, and of her continuing love for him and wishes for regular contact.

While Joy continued to need to mother her mother and to be an auxiliary ego for her, it was felt that Joy progressed as far as she could unless mother pursued her own treatment, which she resisted. Joy responded with acute sadness intermingled with anger during the lengthy termination phase, blaming her mother for its termination as she had blamed her for the loss of the father. She resorted to overtly flirtatious behavior in an attempt to hold onto the therapist. Themes of loneliness were intermingled with those of independence. In her last session, she presented the therapist with a picture of herself as a ballerina and a postcard of geese flying south for the winter.

Follow-up contact: When Joy was 12 , she requested that her mother recontact the clinic, stating that she wanted to resume therapy because "I've been having a bad time with my father." In fact, there had been minimal contact between them for three months, about which she said, "He's a jerk." Her mother described further difficulties as Joy's being extremely stressed with "low moods," tearfulness, restless sleeping, and excessive worry about school performance. Joy had also recently expressed worries about masturbation and fears that her mother would think she were an awful person if she knew. Joy took pride in her A level work in a demanding private school, but on occasion she became upset at school when in the presence of aggressive boys. Mother attributed the bulk of Joy's problems to her father's inattentiveness to her, and she appeared openly critical of the father's lack of child support payments and infrequent contact in front of Joy. In addition, mother made derogatory, denigrating comments in relation to other men as well. The stepfather in the family was depicted as a peripheral, somewhat ineffectual onlooker. Early in re-evaluation,* Joy voiced anger at her natural father as the source of her ongoing difficulty. She denied recalling much of her previous therapy except that "We made Playdoh flowers and now I'm a lot less flaky." She was taking horseback-riding, ballet, and piano lessons. Subsequently, she added that her father was petitioning for joint custody to avoid paying overdue child support, and described boys as pestering girls on an overnight canoe trip. She conveyed that men and boys were untrustworthy pests and then asked if she needed to return to see the male evaluator because she was now feeling a lot better about her father. The next session she asked the evaluator if he had read a book by Thornton Wilder, then in a demeaning fashion said, "You haven't read this and you've been to college?" She had written poetry she wanted to show him after she made a better draft.

*Bob Lizer, M.D., conducted the re-evaluation. 
Her wish and fear around exploring and revealing her feelings in therapy was interpreted, and a recommendation to resume therapy was made. It was postulated that Joy continued to feel a great deal of hunger and longing for a male figure, which became frightening to her as she anticipated rejection and further disappointment. She feared making herself vulnerable if she allowed those feelings to surface.

\section{Role of Therapist as Developmental Facilitator}

The sex of the therapist becomes a more significant dimension in the treatment of the child whose parents have divorced, particularly when living in a single parent household. If the female child is in the custody of the mother, the male therapist becomes a "partial replacement object" who can facilitate the working through of negative feelings about the self resulting from rejection by the oedipal object and oedipal hunger. Chethik and Kalter (1979) refer to the therapist as taking on a special role as a "developmental facilitator" whereby the therapist can help the child patient complete essential developmental tasks. Handling of narcissistic hurt and anger during the termination phase in particular allows for reworking of feelings and defenses associated with the father's departure from the family. A female therapist, on the other hand, may gain easier access to pre-oedipal conflicts in girls, as well as becoming a new object for identification who can facilitate healthy separation from mother. The female therapist may become the transference object for the girl's anger toward the mother for "getting rid of the father" and the developmental anger at the mother for not giving her a penis. With therapists of either sex, a salient treatment issue is how the child who has already had disruptions in ties to parental objects experiences vacation interruptions and termination. In addition to divorce-specific reactions, the therapist of either sex needs to be attentive to pre-divorce developmental conflicts, which may have been poorly resolved, resulting in a vulnerability with which to meet the divorce specific problems.

\section{CONCLUSIONS}

There are a number of critical variables affecting the long-range personality development of girls whose parents have divorced, including pre-divorce personality development, the quality of post-divorce mothering, and the relative availability of the father to serve as a significant male figure in affirming his daughter's femininity. Wallerstein and Kelly (1980) emphasized that in most cases the positive involvement of both parents post-divorce is the most important variable in determining successful adjustments. In their report of five-year post-divorce assess- 
ments, only $30 \%$ of the children were reported to have an emotionally meaningful relationship with their fathers. There needs to be wider recognition that girls have a clear need for ongoing involvement with their fathers (except in the presence of severe mental illness, substance, physical or sexual abuse) to facilitate healthy psychosexual development.

Maintaining effective mothering during divorce proceedings or restoring healthy functioning after a period of disruption can serve as a stabilizing anchor for girls who have tenuous or nonexistent relationships with their fathers. In addition to providing a feminine model for identification, if mother has been able to work through her conflicts in relation to her daughter's father and other males, she can allow her daughter's own fantasies and feelings about her femininity and herself vis-à-vis male objects to evolve over time.

\section{REFERENCES}

Biller, H.B. (1971). Father, Child and Sex Role. Lexington, MA: Heath.

(1981). Father absence, divorce, and personality development. In The Role of the Father in Child Development. Ed 2, ed. M. Lamb. New York: John Wiley and Sons, $489-552$.

Biller, H.B. and Weiss, S. (1970). The father-daughter relationship and the personality development of the female. Journal of Genetic Psychology, 114, 79-93.

Brown, J.K. (1963). A cross-cultural study of female initiation rites. American Anthropologist, 65, 837-853.

Chethik, M. and Kalter, N. (1980). Developmental arrest following divorce. Journal of the American Academy of Child Psychiatry, 19, 281-288.

Edgecombe, R. et al. (1976). Some comments on the negative oedipal phase in girls. Psychoanalytic Study of the Child, 31, 35-61.

Fast, I. (1978). Developments in gender identity: the original matrix. International Review of Psychoanalysis, 5, 265-273.

_ (1979). Development in gender identity: gender differentiation in girls. International Journal of Psychoanalysis, 60, 443-453.

Hetherington, E.M. (1972). Effects of father-absence on personality development in adolescent daughters. Developmental Psychology, 7, 313-326. (1979). Divorce: a child's perspective. American Psychology, 34, 851- 858.

Jacobson, G. and Ryder, R.G. (1969). Parental loss and some characteristics of the early marriage relationship. American Journal of Orthopsychiatry, 39, 779-787.

Kalter, N. (1977). Children of divorce in an outpatient psychiatric population. American Journal of Orthopsychiatry, 47, 40-51.

. (1984). Conjoint mother-daughter treatment: a beginning phase of psychotherapy with adolescent daughters of divorce. American Journal of Orthopsychiatry, 54, $490-497$.

_ et al. (1985). Implications of parental divorce for feminine development. Journal of the American Academy of Child Psychiatry, 24, 538-544.

- and Rembar. (1981). The significance of a child's age at the time of parental divorce. American Journal of Orthopsychiatry, 51, 85-100.

Kulka, R.A. and Weingarten, H. (1979). The long-term effects of parental divorce in childhood on adult adjustment. Journal of Social Issues, 35, 50-78.

Leonard, M.R. (1966). Father and daughters. International Journal of Psychoanalysis, 47, $325-333$.

Mächtlinger, V.J. (1981). The father in psychoanalytic theory. In The Role of the Father in Child Development. Ed. 2, ed. M. Lamb. New York: John Wiley \& Sons. 
REBECCA LOHR ET AL.

Mendell, A.E. (1983). Play therapy with children of divorced parents. In Handbook of Play Therapy. ed. Schaefer and O'Connor. New York: John Wiley \& Sons, pp. 320-354.

Neubauer, P.B. (1960). The one-parent child and his oedipal development. The Psychoanalytic Study of the Child, 15, 286-309.

Stephens, W.N. (1962). The Oedipus Complex and Cross-Cultural Evidence. Glencoe, IL: Free Press.

Wallerstein, J.S. (1984). Children of divorce: Preliminary report of a 10-year follow-up of young children. American Journal of Orthopsychiatry, 54, 444-458.

. (1985). Children of divorce: Preliminary report of a 10-year follow-up of older children and adolescents. Journal of the American Academy of Child Psychiatry, 24, $545-553$.

and Kelly J. (1975). The effects of parental divorce: Experiences of the preschool child. Journal of the American Academy of Child Psychiatry, 14(4), 600-616.

(1976). The effects of parental divorce: Experience of the child in later latency. American Journal of Orthopsychiatry, 46, 256-269.

(1980). Surviving the Break-Up: How Children Actually Cope with Divorce. New York: Basic Books, 1980.

Rebecca Lohr M.S.W.

Child and Adolescent Psychiatry

Dept of Psychiatry

University of Michigan Medical Center

Ann Arbor, MI 48109 